\title{
La fórmula «pro multis»: perspectiva bíblica y dogmática
}

\author{
The «pro multis» Consecratory Formula: Biblical and \\ Dogmatic Perspective
}

\begin{abstract}
Antonio DUCAY
Pontificia Università della Santa Croce. Facoltà di Teologia

Roma. Italia

ducay@pusc.it
\end{abstract}

\section{Pablo GONZÁLEZ-AlONSO}

Universidad de Navarra. Facultad de Teología

Pamplona. España

pgonzaleza@unav.es

Resumen: En la traducción al español de la fórmula de consagración del cáliz se ha sustituido la expresión «por todos los hombres» con «por muchos». En este artículo se analiza brevemente esta fórmula desde dos perspectivas: la exegética y la dogmática. Se analizan los textos del Nuevo Testamento y el fundamento que ofrecen para el cambio establecido, y se considera el alcance teológico que tiene. Se pone de relieve que el cambio en la fórmula no obedece a motivos estrictamente doctrinales, puesto que la sangre de Jesús se derrama efectivamente por todos los hombres, y se subraya, sin embargo, que la nueva traducción facilita deshacer el equívoco de que la salvación es algo casi «automático», que apenas depende de la libre cooperación del hombre.

Palabras clave: pro multis, Consagración, Eucaristía.
Abstract: In the Spanish translation of the chalice's consecratory formula, the expression «por todos los hombres» has been substituted by «por muchos». This article briefly analyzes the formula from both the exegetical and the dogmatic standpoints. It examines some New Testament passages and the foundation they provide for the approved change and considers its theological scope. This article also insists that, since Jesus' blood is shed for all mankind, this change of formula is not due to purely doctrinal reasons and underlines that the new translation makes it easier for one to rectify the erroneous conception that salvation is something «automatic» which hardly depends on man's free cooperation.

Keywords: pro multis, Consecration, Eucharist. 


\section{INTRODUCCIÓN}

a tercera edición del Misal Romano, recientemente presentada públicamente en España, tiene entre sus principales novedades un cambio en la liturgia eucarística. La expresión «por todos los hombres» que aparece en la consagración del vino, será sustituida a partir del primer domingo de cuaresma de 2017 por la expresión «por muchos». ¿Cuáles son las razones de este cambio? Un poco de historia será aquí de utilidad.

En la liturgia romana, en latín, la expresión utilizada era «pro multis» y así seguía apareciendo en el Misal reformado después del Vaticano II y promulgado por Pablo VI. Pero al verter los textos litúrgicos a las lenguas vernáculas, la expresión pro multis de la consagración fue traducida, en algunos casos, con un cambio de matiz: «por todos los hombres» (for all, per tutti, für alle...), con el deseo de expresar el valor universal del sacrificio redentor de Cristo. Este hecho es el que ahora ha sido objeto de revisión y ha dado lugar a las nuevas disposiciones litúrgicas. Con el paso de los años se ha visto que esta opción no se ajustaba a los criterios mantenidos en la traducción del resto del Misal Romano y de los Leccionarios, en los que se buscó una mayor literalidad respecto de los textos originales ${ }^{1}$.

Por este motivo, la Congregación para el Culto Divino y Disciplina de los Sacramentos hizo en julio de 2005 una consulta a los Presidentes de las Conferencias Episcopales acerca de la traducción del pro multis en la fórmula de consagración de la Sangre de Cristo en las distintas lenguas vernáculas. A partir de las respuestas recibidas, en octubre de 2006 el Cardenal Arinze, entonces Prefecto de dicha Congregación, emitió una Carta circular exponiendo breve y ordenadamente los «muchos argumentos a favor de una versión más precisa de la tradicional fórmula pro multis» (n. 3) ${ }^{2}$. En ella se hacía especial hincapié en que «la fórmula usada en la narración de la institución es "por muchos"» y en que «el rito Romano, en latín, ha dicho siempre pro multis». Por estos motivos, entre otros, se mostraba la conveniencia de atenerse a una traducción más fiel al texto bíblico y a la tradición (por muchos, for many, per multi, für viele...).

En consecuencia, la Carta circular instaba (n. 4) a «las Conferencias de Obispos de aquellos países donde la fórmula "por todos" o sus equivalentes

${ }^{1}$ Congregación Para el Culto Divino, «Liturgiam authenticam», 28-III-2001, Notitiae. Boletín de la congregación para el culto divino 38 (2002) 65-119.

2 Congregación Para el Culto Divino, «Carta a los presidentes de las conferencias episcopales», 17 X-2006, Notitiae. Boletín de la congregación para el culto divino 42 (2006) 441-458. 
está actualmente en uso» a «introducir una traducción precisa, en lengua vernácula, de la fórmula pro multis», en la próxima traducción de la editio typica tertia del Missale Romanum, que había sido aprobada por el papa Juan Pablo II en el año $2000^{3}$. En este contexto, en marzo de 2012, el Presidente de la Conferencia Episcopal Alemana, el arzobispo Robert Zollitsch, informó a Benedicto XVI de que algunos sectores del ámbito lingüístico alemán deseaban mantener la traducción «por todos», aun cuando la Conferencia Episcopal Alemana acordase traducir «por muchos», tal y como había sido indicado por la Santa Sede. Ante esta situación, el Papa, con el fin de prevenir una división en la traducción de las palabras centrales de la Plegaria Eucarística, elaboró una carta en la que explicaba el porqué de la nueva traducción y los motivos que la hacían conveniente ${ }^{4}$. Al redactar esta enseñanza, apremiaba a los obispos alemanes -y de todo el mundo- a poner definitivamente en marcha las indicaciones emitidas por la Congregación para el Culto Divino en la Carta del Card. Arinze del 17 de octubre de 2006.

En este marco, como fruto de un largo trabajo de revisión y actualización, siguiendo las indicaciones emitidas por la Congregación para el Culto Divino, la Conferencia Episcopal Española ha presentado recientemente la nueva edición oficial en español del Misal Romano. Se trata pues de la versión castellana de la editio typica tertia emendata del Missale Romanum, publicada en 2008, en la que se modifica la traducción de las palabras de la consagración: la expresión «por todos los hombres» que hasta ahora se utilizaba queda sustituida por la traducción más literal del texto latino «por muchos».

La cuestión de la fórmula de la consagración del cáliz en la celebración eucarística engloba aspectos de diversa índole: exegéticos, litúrgicos, pastorales y doctrinales ${ }^{5}$. En ámbito exegético se trata de determinar quiénes son,

\footnotetext{
3 Se trata de la tercera edición típica del Misal Romano, promulgado el 3 de abril de 1969, por el papa Pablo VI, y renovado por el papa Juan Pablo II en esta tercera edición, publicada en 2002 y que, a su vez, en 2008 fue publicada de nuevo con algunas modificaciones.

4 BeNEDicto XVI, «Carta al Presidente de la Conferencia Episcopal Alemana sobre la traducción de "pro multis"», 14-IV-2012, Pastoral litúrgica. Documentación. Información 328-329 (2012) 81-86.

5 La bibliografía sobre el tema es amplia. Señalamos entre otros: GIRAUDO, C., «"Pro vobis et pro multis". La parole istituzionali tra quello che ha detto Gesù e quello che possiamo leggervi noi», Gregorianum 93 (2012) 677-709; HAUKE, M., «Shed for the Many. An Accurate Reading of the Pro Multis in the Formula of Consecration», Antiphon 14 (2010) 169-229; MonZIo CompaGNONI, G., «La formula "pro vobis et pro multis". Note sull'origine e considerazioni sulla traduzione», Ephemerides Liturgicae 128 (2014) 48-103; PIERI, F., Per una moltitudine. Sulla traduzione delle parole eucaristiche, Bologna: Dehoniane, 2012; ProsingER, F., «Le sang de l'Alliance répandu "pour tous" ou "pour beaucoup?"», Sedes Sapientiae 87 (2004) 53-70.
} 
para los evangelistas Mateo y Marcos, los destinatarios de la sangre de la Alianza que Jesús iba a derramar «por muchos». Tras esta pregunta está, naturalmente, la cuestión de cómo entendió Jesús su gesto en la Última Cena y en quiénes pensaba mientras entregaba el cáliz a sus discípulos (los relatos eucarísticos de Lucas y Pablo no contienen el «por muchos», en ellos Jesús dice simplemente «por vosotros»). La cuestión litúrgica, en cambio, se preocupa más bien de si, a la hora de traducir el Misal latino a las lenguas vernáculas, conviene privilegiar la literalidad del texto o su sentido, y en este último caso, si el sentido debe referirse al texto bíblico o al contexto, más amplio, de la doctrina de la Iglesia sobre el valor de la muerte de Jesús. En el terreno pastoral se sabe que cada cultura tiene sus gustos y sus fobias particulares, y puede tender hacia comprensiones rigoristas o, al contrario, relajadas de las condiciones necesarias para alcanzar la salvación; la fórmula de la consagración incide sobre este aspecto, pues contribuye a generar una mentalidad en una u otra dirección. Finalmente en el ámbito doctrinal la cuestión se plantea en términos de quiénes fueron, en definitiva, los destinatarios de la muerte de Cristo: ¿murió por todos los hombres o sólo por los creyentes? ¿Por todos o sólo por los que efectivamente se salvan? Y ¿cómo entender más precisamente estas expresiones: sangre derramada «por muchos»; sangre derramada «por todos»? En este artículo presentaremos la cuestión tanto desde el punto de vista exegético como dogmático abordando aquellos aspectos más destacados por la nueva regulación litúrgica.

\section{La fórmula pro multis en el Nuevo Testamento}

En la exégesis contemporánea, es común afirmar que las palabras de Jesús en la institución de la Eucaristía son probablemente las palabras del Nuevo Testamento mejor atestiguadas desde un punto de vista histórico-crítico. Bajo este supuesto, se podría esperar que los relatos de la Última cena -hemos recibido cuatro- fueran iguales. Sin embargo, se pueden apreciar claramente dos tradiciones, cercanas pero diversas ${ }^{6}$. Parece claro que la palabras griegas que conservamos no son las ipsissima verba Iesu, pronunciadas en arameo. Por otro lado, las expresiones que nos han llegado a través de los tres evangelios sinópticos (Mt 26,26-29; Mc 14,22-26; Lc 22,18-20) y Pablo (1 Cor 11,23-25) difieren en

\footnotetext{
${ }^{6}$ Cfr. Bovon, F., El Evangelio según San Lucas, IV, Salamanca: Sígueme, 2010, 273-274.
} 
algunas fórmulas: en concreto, en Mateo y Marcos la sangre es derramada «por muchos»; en Lucas y Pablo, lo es «por vosotros»; en Mateo y Marcos se habla de «mi sangre de la alianza», mientras que en Lucas y Pablo se dice de «la nueva alianza en mi sangre», etc. A favor de la fidelidad de la transmisión está el hecho del sabor arameo original de las palabras: la crítica ha hecho notar que los textos están llenos de semitismos; por ejemplo, en el breve relato de Marcos los estudiosos han descubierto hasta veintitrés 7 . Por otra parte, las diferencias entre la tradición de Pablo y Lucas, más helenista, y la de Mateo y Marcos, más judía, se pueden explicar fácilmente por el contexto de la transmisión de la tradición. Parece claro, por tanto, que si bien no tenemos acceso a las palabras exactas de Cristo, sí alcanzamos la ipsissima vox Iesu transmitida por los primeros discípulos y recogida en el Nuevo Testamento ${ }^{8}$.

Un examen más detenido de las mismas fórmulas señala la fidelidad y la actualización de la tradición. Parece claro a todos que el Sitz im Leben de la transmisión de la tradición de las palabras del Señor es el litúrgico: la misma invitación de Jesús para realizar los gestos «en memoria (’’ $\left.\alpha_{\alpha}^{\prime} \mu \nu \eta \sigma \iota \varsigma\right)$ mía», recogida por Lc 22,29 y 1 Cor 11,24.25, tiene este carácter autoreferencial: la comunidad apostólica, en su vida cristiana, repite los gestos de Cristo como obediencia a las palabras de Cristo incluidas en el mismo gesto. Además, san Pablo recuerda expresamente que esto es una tradición que recibió del mismo Señor (1 Cor 11,23). Las diferencias más notables, como se ha dicho arriba, se presentan entre las dos tradiciones: la de Mateo y Marcos por una parte y la de Pablo y Lucas por otra. Es decir, no proceden de una posible evolución de la tradición, pues, cronológicamente, los textos más antiguos son los de Pablo y Marcos, representantes cada uno de ellos de una orientación de la tradición. Las divergencias tienen que ver más bien con el medio en el que se produce la tradición.

La primera diferencia aparece en la fórmula sobre el pan. En Mateo y

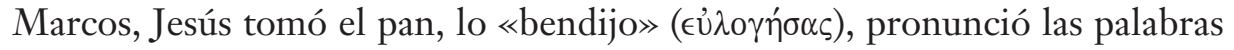

\footnotetext{
O’Toole, R. F., «Last supper», Anchor Bible Dictionary 4 (1992) 235; cfr. JeremIAs, J., La Última Cena: Palabras de fesús, Madrid: Cristiandad, 1980, 194-198.

${ }^{8}$ Cfr. Jeremias, J., La Última Cena: Palabras de fesús, 220-221. Por otra parte, como recordaba Benedicto XVI, «la transmisión de las palabras de Jesús no existe sin su recepción por parte de la Iglesia naciente, que se sabía rigurosamente comprometida en la fidelidad en lo esencial, pero que también era consciente de que el ámbito de resonancia de las palabras de Jesús, con sus correspondientes alusiones sutiles a textos de la Escritura, permitía algún retoque en los matices» (Benedicto XVI/Ratzinger, J., Fesús de Nazaret: Desde la Entrada en Ferusalén hasta la Resurrección, 152-153).
} 
y lo dio a los discípulos; en Lucas y Pablo, en cambio, no se habla de la ben-

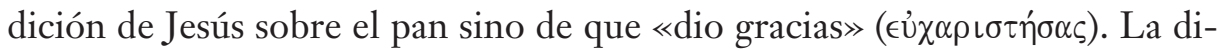
ferencia entre los dos verbos, perceptible en otros lugares de los evangelios sinópticos, no apunta a una divergencia sino a un hecho transmitido de una doble manera ${ }^{9}$. En la fórmula sobre el vino hay dos diferencias claras. En

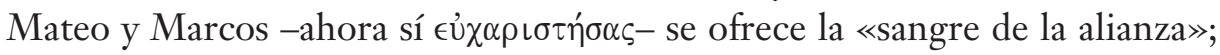
en Lucas y Corintios el cáliz es la «nueva alianza en mi sangre». La segunda divergencia, que nos ocupará desde ahora, se refiere a que en Mateo y Marcos, la sangre se ofrece «por muchos» frente al «por vosotros» de Lucas y Pablo (aunque en este «por vosotros» se pronuncia únicamente sobre el pan: 1 Cor 11,24).

En lo que se refiere al hecho mismo de la «sangre» de la «alianza», el trasfondo veterotestamentario es evidente. Aunque las dos palabras pueden evocar textos distintos ${ }^{10}$, no dejan ambas de hacer referencia al aspecto sacrificial que mantiene la unidad entre ellas ${ }^{11}$. Ambas tradiciones neotesta-

${ }^{9}$ En ocasiones se ha discutido si las palabras eran una bendición sobre el pan en lugar de una acción de gracias a Dios; se puede encontrar una explicación en LUZ, U., El Evangelio según San Mateo, IV, Salamanca: Sígueme, 2005, 165-167. De todas formas, en las multiplicaciones de los panes recogidas por Mateo y Marcos, de manera muy significativa, en los dos evangelios se dice que en la primera multiplicación (Mt 14,19-20; Mc 6,41-43) Jesús pronunció la bendición y lo sobrante fueron doce canastos; en la segunda (Mt 15,36-37; Mc 8,6-8), en cambio, Jesús da gracias y lo sobrante son siete cestos. Tanto las palabras como los números y como otros rasgos señalan los horizontes judeocristianos y helenistas, respectivamente (cfr. CASCIARO, J. M. [ed.], Sagrada Biblia, V, Pamplona: Eunsa, 2008, 295-296).

10 En el caso de Mt-Mc se apoya en Ex 24,8, mientras que Lc-1 Cor parecen seguir expresiones de Jr 31,31 (cfr. Benedicto XVI/RATZINGER, J., Fesús de Nazaret: Desde la Entrada en ferusalén hasta la Resurrección, 151-153). En cualquier caso, «all three accounts preserve early tradition: none is significantly closer to the original form than the other» según DAVIES, W. C. y ALLISON, D. C., The Gospel According to Saint Matthew, III, London: T\&T Clark, 2004, 466, quien añade a pie de página: «Both can at any rate be retrojected into Aramaic», apoyándose en FITZMYER, J. A., El Evangelio según Lucas, IV, Madrid: Cristiandad, 2005, 326.

11 «Aun cuando no se dice "ésta es mi sangre, la sangre de la alianza", como en Mc 14,24 con su clara alusión a Ex 24,8, la identificación de la copa de vino con "la Nueva Alianza sellada con mi sangre" no es menos alusiva al sacrificio que sella la Alianza en Ex 24,3-8 que la formulación de Marcos, a pesar de que aquí se presente recargada con una alusión a Jr 31,31: "la nueva alianza” ( FITZMYER, J. A., El Evangelio según Lucas, IV, 323). La alianza va más allá del pacto entre Israel y Dios, pues también tiene un carácter expiatorio (cfr. PESCH, R., Il Vangelo di Marco, II, Brescia: Paideia, 1982, 531-532). «Tratándose de la sangre de Fesús, está claro implícitamente que la alusión a Ex 24,8 tiene carácter tipológico y hace referencia a una alianza distinta de la se-

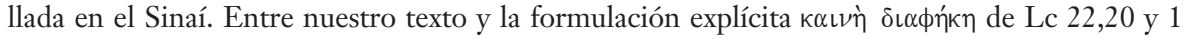
Cor 11,25 no hay, por tanto, una diferencia de principio» (LuZ, U., El Evangelio según San Mateo, IV, 177). También, cfr. GNILKA, J., El Evangelio según San Marcos, II, Salamanca: Sígueme, 1986, 287. 
mentarias suponen una actualización litúrgica de la institución de la Eucaristía por Jesús ${ }^{12}$. Por eso, aunque son diversas, no son contradictorias. Esta actualización litúrgica es la que puede explicar mejor la aparición del pro vobis de Lucas y Pablo frente al pro multis de Mateo y Marcos. Los dos primeros evangelistas reflejan una actualización de la tradición de las palabras pronunciadas por Jesús; Lucas y Pablo transmiten una recepción «fraseológica» tomada del contexto litúrgico y celebrativo ${ }^{13}$. En realidad, según el parecer de los estudiosos, en el contexto de la Cena el «por vosotros» se identifica con el «por muchos»: el sacrificio de Cristo no estaba dirigido únicamente a quienes estaban con Él en el cenáculo (vobis), sino a todos los hombres (multis $)^{14}$. Se incluyen los presentes sin perder la «tensión» universal del sacrificio: vobis recoge a los presentes pero que, por la actualización del sacrificio, serán todos aquellos que estén participando a lo largo de toda la historia, y multis resalta el propósito de dar los frutos de su muerte en la cruz a todos los creyentes a lo largo de todos los siglos ${ }^{15}$. El «juego del yo y el vosotros» en Lucas refleja la comunión que Cristo establece con su Iglesia a partir de la Última cena ${ }^{16}$.

El siguiente paso tiene que examinar qué sentido tiene el pro multis de Mateo y Marcos. Los dos evangelios, además de usarlo en el texto de la Cena

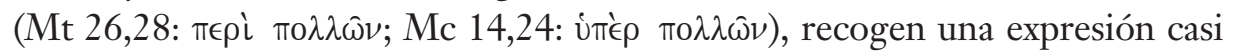
idéntica en las palabras de Jesús tras la reprensión a los Zebedeos: «El Hijo Hombre no ha venido a ser servido, sino a servir y dar su vida en redención de muchos ( $\lambda \dot{u} \tau \rho o \nu \dot{\alpha} \nu \tau \grave{\imath} \pi 0 \lambda \lambda \omega \hat{\omega} \nu) \gg($ Mt 20,28; Mc 10,45). ¿Cuál es el significado de este «muchos»? Los contextos inmediatos de los dos evangelios, en las dos ocasiones en que ponen las palabras en boca de Jesús, señalan claramente el sentido vicario, sacrificial y expiatorio del término. Probablemente remiten al

12 «The Lord's Supper is an aetiological cult narrative (...). Is an example of how the text gives its full meaning only to readers who bring to it extra-textual knowledge, in this case knowledge of the Christian celebration of the Eucharist» (Davies, W. C. y Allison, D. C., The Gospel According to Saint Matthew, III, 465). También, cfr. LuZ, U., El Evangelio según San Mateo, IV, 154; cfr. Jeremias, J., La Última Cena: Palabras de Jesús, 118-121.

13 Para Jeremias, el $\dot{u} \mu \omega \hat{v}$ tiene un carácter interpelativo, propio del ámbito litúrgico, por lo que

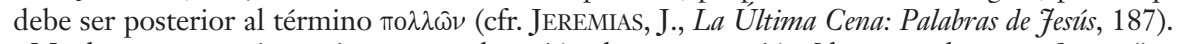

$14 \ll$ Muchos comentaristas piensan que la unión de esa expresión [derramar la sangre] con "por vosotros/por la multitud" implica una alusión al cuarto cántico del Siervo de Yahvé» (FITZMYER, J. A., El Evangelio según Lucas, IV, 340).

15 Por ejemplo, en Lc 22,20 «la presencia de los apóstoles simboliza el nuevo pueblo de Dios con el que se va a establecer la "Nueva Alianza"» (FITZMYER, J. A., El Evangelio según Lucas, IV, 329).

${ }^{16}$ Cfr. Bovon, F., El Evangelio según San Lucas, IV, 284. 
cuarto poema del Siervo del Señor descrito por Isaías (Is 52,13-53,14), donde

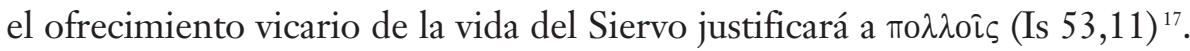

Para una gran mayoría de autores, Jesús, si no se identificó expresamente con el Siervo del Señor de Isaías, lo consideró cuando menos en el horizonte de su misión y, evidentemente, se sirvió de la fraseología. En consecuencia, así lo recogieron los evangelios. El más explícito es Mateo que, en un contexto judío, está lleno de alusiones y citas explícitas del Antiguo Testamento. En su narración se apoya frecuentemente en Jeremías, Zacarías o Ezequiel, pero, sobre todo, en Salmos e Isaías, teniendo este último un papel importante en el conjunto del mensaje del evangelio. Mateo va más allá de las citas para reforzar su composición; parece que tiene en cuenta todo el libro de Isaías y sus enseñanzas a la hora de escribir el evangelio ${ }^{18}$. Además de muchas posibles alusiones, hay nueve citas directas, de las cuales dos están referidas a las curaciones de Jesús haciendo referencia a poemas del Siervo (Is 53,4 / Mt 8,17; Is 42,1-4 / Mt 12,18-21), que señalan tanto su identidad como su cuidado de la humanidad ${ }^{19}$. Para algunos autores, Mt 20,28 remite inmediatamente al Siervo ${ }^{20}$ y constituye un contexto apropiado para Mt 26,28; otros, matizan la afirmación ${ }^{21}$.

${ }^{17}$ Sobre la discusión acerca de la relación entre Mc 10,45 y el Siervo del Señor puede verse: McKnight, S., Fesus and His Death. Historiography, the Historical fesus, and Antonement Theory, Waco [TX]: Baylor University Press, 2005, 68-70.

18 «They are used in a highly sophisticated manner that imparts to the gospel intricate layers of meaning. They represent the exegesis of the early Christian movement and its attempt to come to terms with the life, work and person of Jesus, the Messiah, son of Abraham, son of David» (Beaton, R., «Isaiah in Matthew's Gospel», en Moyise, S. y Menken, M. J. J. [eds.], Isaiah in the New Testament, London: T\&T Clark, 2005, 76).

${ }^{19}$ Cfr. Beaton, R., «Isaiah in Matthew's Gospel», 63-78. En su comentario a Isaías, Childs sumariza la interpretación de la figura del Siervo del Señor en el judaísmo precristiano (CHILDS, B. S., Isaiah, Louisville: Westminster John Knox Press, 2001, 420). Para autores como Hengel o Stuhlmacher, el Siervo era entendido como una figura individual, lo que explicaría mejor su identificación con Jesús en su papel vicario. En cambio, otros autores como Bultmann o Käsemann consideran que las alusiones a Is 53 son vagas y que la relación entre Jesús histórico y la figura del Siervo es resultado de una interpretación del cristianismo helenista posterior.

$20 \ll$ Our line clarifies 20.28, with which it shares mo $\lambda \lambda \hat{\omega} \nu$ : the "ransom for many" is made through sacrificial blood» (DAVIES, W. C. y Allison, D. C., The Gospel According to Saint Matthew, III, 474).

21 «"For many" and "poured out" likely advert to Isa 53.12 and so imply that Jesus in his death is the suffering servant of Isaiah» (DAVIES, W. C. y Allison, D. C., The Gospel According to Saint Matthew, III, 465), y «20.28 is only one of a network of Matthean texts that cite or allude to Isa 52.13-53.12, the fourth servant song» (ibíd., III, 96).

En cambio, para Ulrich Luz la referencia a Is 53 es muy problemática porque apenas se constatan coincidencias verbales; por eso prefiere interpretar no $\lambda \lambda$ oí en el contexto inmediato, como referido a la comunidad (LUZ, U., El Evangelio según San Mateo, III, 223 y IV, 178). 
Ahora bien, es precisamente el texto de Isaías 52,13-53,12 el que provoca la ambigüedad. Is 53,11 dice que el siervo «justificará a muchos (סיבר: rabbim) y cargará con sus culpas». Ahora bien, en hebreo no existe la connotación dialéctica entre «muchos»y «todos», pues «la palabra סיבר significa solamente un gran número, sin especificar si este gran número corresponde o no a todos» ${ }^{22}$; en todo caso, en hebreo la multitud no es necesariamente contradictoria con la totalidad ${ }^{23}$. Si Jesús estuviera citando expresamente el texto de Is 53,11 , por identificarse expresamente con el siervo del Señor, ¿no podría interpretarse el rabbim en sentido restrictivo? De acuerdo con la interpretación de la misión del siervo se podría decir que la referencia a la totalidad no es del todo expresa; ahora bien, en el contexto de las mismas enseñanzas de Jesús, especialmente cuando se predica a sí mismo como Siervo del Señor y como Hijo del Hombre, la universalidad es mucho más clara ${ }^{24}$. Por eso, si nos atenemos a los textos bíblicos, parece claro que el horizonte del Nuevo Testamento es el de la totalidad: antes de la Pascua podría ser el de la totalidad de Israel y tras la Pascua sería la totalidad de los hombres ${ }^{25}$.

El uso paulino de las expresiones y conceptos invocados se puede interpretar en la misma línea que los textos recogidos en los evangelios. $\mathrm{El} \ll \mathrm{mu}-$ chos» convive con el «todos», con el mismo sentido que en las frases de Jesús. Así 1 Cor 10,33: «Haced como yo, que me esfuerzo por complacer a todos en todas las cosas ( $\pi \dot{\alpha} \nu \tau \alpha \pi \hat{\alpha} \sigma \iota \nu / o m n i a$ omnibus), no buscando mi interés personal,

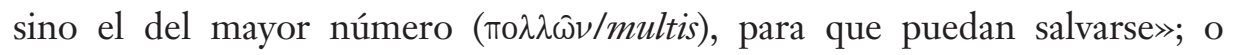

22 VANHOYE, A., «La traducción del pro multis», 312.

${ }^{23}$ Childs lo traduce e interpreta como «multitud» (cfr. CHILDS, B. S., Isaiah, 419-420). El significado de totalidad le parece claro a Jeremias, J., La Última Cena: Palabras de fesús, 194-195.

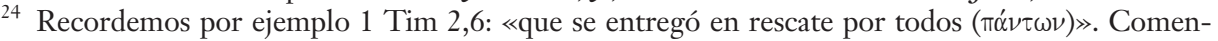
tan a este propósito Davies y Allison: «The variant of our saying [Mt 20.28] in 1 Tim 2.6 has $\pi \alpha \dot{v} \tau \omega \nu$, because $\pi 0 \lambda \lambda o$ i elsewhere in the NT sometimes seems to mean "all" (e.g. Rom 5.15,19), and because one can identify the "many" as all except the Son of man, one should probably give mo $\lambda \lambda$ oí comprehensive meaning» (DAVIES, W. C. y Allison, D. C., The Gospel According to Saint Matthew, III, 95). De modo parecido Benedicto XVI: «Sólo podemos decir que Él sabía que en su persona se cumplía la misión del siervo de Dios y la del Hijo del hombre, por lo que la conexión entre los dos motivos comporta al mismo tiempo la superación de la limitación de la misión del siervo de Dios, una universalización que indica una nueva amplitud y profundidad» (Benedicto XVI/Ratzinger, J., Fesús de Nazaret: Desde la Entrada en Ferusalén hasta la Resurrección, 163).

25 Cfr. Pesch, R., Il Vangelo di Marco, II, 532-533. También así Benedicto XVI: «Si en Isaías "muchos" podía significar esencialmente la totalidad de Israel, en la respuesta creyente que da la Iglesia al nuevo uso de la palabra por parte de Jesús queda cada vez más claro que Él, de hecho, murió por todos» (BenEDICTO XVI/Ratzinger, J., Fesús de Nazaret: Desde la Entrada en Ferusalén basta la Resurrección, 164). 
Heb 9,28: «Así también Cristo, después de haberse ofrecido una sola vez para quitar los pecados de la multitud (по $\lambda \lambda \omega \hat{\omega} /$ multorum), aparecerá por segunda vez, ya no en relación con el pecado, sino para salvar a los que lo esperan», etc. El sentido de totalidad campea por lo demás, por todo el Nuevo Testamento: Rom 5,14; 2 Cor 15,15; 1 Tim 2,6; etc.

Las palabras de Jesús en la Última cena se refieren a una Alianza que, sin duda, remite a la de Moisés en Ex 24,8, realizada por muchos, pero a la luz de la nueva Alianza proclamada en Jr 31,31. Ahora bien, la alianza antigua no era una alianza de perdón de los pecados, ni de expiación como ésta que realiza Jesús: la expiación universal de Jesús le sitúa como mediador universal ${ }^{26}$. La inclusión en un mismo sintagma del pro vobis et pro multis en la liturgia, a partir de dos fuentes autónomas, tiene un cierto componente de libertad, pero no de arbitrariedad: tiene su base bíblica y es resultado de una tradición multisecular $^{27}$. La expresión latina cuya traducción literal aparecerá ahora en la traducción castellana, respeta el sentido y el vocabulario neotestamentario, cuyo significado sin duda es el expresado por la dogmática: Cristo murió por todos, lo que no asegura automáticamente que todos, subjetivamente, cada uno, lleguemos a acoger este don.

\section{2. «POR MUCHOS», «POR TODOS»: PERSPECTIVA DOGMÁTICA}

Que Jesús murió por todos los hombres está suficientemente testimoniado en la Sagrada Escritura. Benedicto XVI se expresaba en este sentido en una carta dirigida al Presidente de la Conferencia Episcopal alemana con motivo del «pro multis»:

$\ll$ El hecho de que Jesucristo, en cuanto Hijo de Dios hecho hombre, sea el hombre para todos los hombres, el nuevo Adán, forma parte de las certezas fundamentales de nuestra fe. Sobre este punto, quisiera recordar solamente tres textos de la Escritura: Dios entregó a su Hijo "por todos", afirma Pablo en la Carta a los Romanos (Rom 8,32). "Uno murió por todos", dice en la Segunda Carta a los Corintios, hablando de la

${ }^{26}$ Cfr. GNILKa, J., El Evangelio según San Marcos, II, 287-288.

27 «En las palabras elegidas para la consagración, la Iglesia ha procedido con cierta libertad como para pensar que son las mismas palabras pronunciadas por Jesús» (VANHOYE, A., «La traducción del pro multis», 315); cfr. GIRAUDO, C., «Pro vobis et pro multis: Le parole istituzionali tra quello che ha detto Gesù e quello che possiamo leggervi noi», 689. 
muerte de Jesús (2 Cor 5,14). Jesús “se entregó en rescate por todos”, escribe en la Primera Carta a Timoteo $(1 \operatorname{Tim} 2,6){ }^{28}$.

Efectivamente, si el primer Adán fue causa de perdición para todos los hombres, es lógico que Jesús, nuevo Adán, sea causa de salvación para todos los hombres, máxime cuando, como dice san Pablo, «donde abundó el pecado sobreabundó la gracia» (Rom 5,20). Puesto que la Escritura contiene afirmaciones claras sobre el alcance universal de la muerte de Cristo no es sorprendente que la idea sea testimoniada en escritos de los Padres -como san Juan Crisóstomo ${ }^{29}$ - o en algunas de las plegarias eucarísticas antiguas ${ }^{30}$. Desde entonces la Iglesia siempre ha mantenido que Jesús murió por todos; una afirmación que se encuentra textualmente en el último concilio ecuménico ${ }^{31}$. Pero, al mismo tiempo, ha sostenido también que de ahí no se puede deducir que la salvación se conceda de modo automático a todos los hombres, pues sólo se salvarán quienes, guiados por la gracia de Dios y apoyados en ella, pongan los medios necesarios para alcanzar esa salvación que Cristo ofrece ${ }^{32}$. Por

${ }^{28}$ Benedicto XVI, «Carta al Presidente de la Conferencia Episcopal Alemana sobre la traducción de "pro multis"», 14-IV-2012, Pastoral litúrgica. Documentación. Información 328-329 (2012) 8186 (aquí 85). Otras fórmulas del Nuevo Testamento de corte universalista: Jn 1,29; 4,42; 6,51; 1 Jn 2,2; 4,14; 1 Pe 3,18 .

29 «"Se inmoló una sola vez". ¿Quién fue el oferente? Evidentemente se ofreció Él mismo. De modo que aquí se muestra no sólo sacerdote sino también víctima del sacrificio. Después se añade la causa por la que fue inmolado. Se dice: "Una sola vez se ofreció en sacrificio para soportar los pecados de muchos". ¿Por qué dice: de muchos y no de todos? Porque no todos creyeron. Por lo que de Él dependía, murió por todos, para salvarlos a todos. Su muerte era suficiente a impedir la perdición de todos; si no pudo tomar sobre sí los pecados de todos fue porque ellos no quisieron», JUAN CRISÓstomo, In Heb. Hom., 9,28: PG 63.129. Traducción nuestra.

30 Por ejemplo la anáfora caldea de Teodoro (de Mopsuestia) y la liturgia de S. Basilio, siguiendo a S. Juan, ponen en relación los dones eucarísticos (el cuerpo y la sangre) con «la vida del mundo». Cfr. Hauke, M., «Shed for the Many. An Accurate Reading of the Pro Multis in the Formula of Consecration», 192. Este autor afirma también que, antes de la reforma introducida por el concilio Vaticano II, las palabras consagratorias de Jesús nunca habían sido traducidas litúrgicamente con la expresión «por todos». Ibíd.

31 «Cristo murió por todos, y la vocación suprema del hombre en realidad es una sola, es decir, la divina», Concilio Vaticano II, Constitución Pastoral, Gaudium et Spes, 22.

32 El pecado se trasmite automáticamente junto con la naturaleza, de tal modo que, salvo una particular previsión de Dios, cada uno nace privado de la gracia divina. En cambio, el fruto principal de la muerte de Cristo, la gracia de la adopción filial (o el don de la justificación), no es automática, pues necesita de una adhesión que tiene carácter «personal». Requiere, de algún modo, el deseo libre de la criatura, y no se obtiene si no se desea o si se rechaza explícitamente. En ese sentido el concilio de Trento afirma que «la fe es el principio de la salvación, el fundamento y la raíz de toda justificación», CONCILIO DE Trento, Sesión VI, Decreto sobre la justificación, 13-I-1547, cap. 8, DH 1532. 
este motivo, esos mismos documentos que hablan del alcance universal de la salvación obrada por Cristo, relacionan esta salvación con la fe en Jesús ${ }^{33}$. En definitiva, no se deben oponer las dos posiciones (la muerte por todos versus la muerte por los creyentes) puesto que los dos aspectos -el objetivo: la muerte de Jesús por todos; el subjetivo: la acogida en la fe del carácter salvador de esa muerte- forman parte de la realidad revelada.

\subsection{Dios a favor de algunos, Dios a favor de todos}

En la historia cristiana no han sido infrecuentes las posiciones que tendían a eliminar uno de estos dos aspectos, ya fuera limitando el alcance de la muerte de Cristo sólo a algunos predestinados o bien, al contrario, pensando que no era posible la existencia de condenados, pues todos terminarían por salvarse de un modo u otro en virtud del sacrificio de Cristo. En el siglo IX el monje Godescalco sostuvo que Dios predestinaba a los elegidos a la salvación y a los demás a la condenación eterna, posición que fue rechazada por el sínodo de Quercy del año $849^{34}$. Mayor importancia tuvo la posición de los reformadores protestantes. Desde una perspectiva de la soberanía absoluta de Dios sobre el mundo y de la completa imposibilidad por parte del hombre de colaborar en la propia salvación, Juan Calvino concluía que era Dios quien decidía todo. La voluntad activa de Dios disponía el corazón humano para la salvación o, al contrario, lo endurecía, de modo que todos, buenos y malos, servían así a sus designios. Por tanto era también Dios quien desde el inicio elegía a algunos y los predestinaba a la salvación, o bien los rechazaba y los destinaba a la condenación ${ }^{35}$. Teodoro Beza († 1605), que sucedió a Calvino a

${ }^{33}$ Un dossier casi exhaustivo, que muestra bien ambos aspectos, se puede consultar en el estudio, ya citado, de Hauke, M., «Shed for the Many. An Accurate Reading of the Pro Multis in the Formula of Consecration», 169-229 (espec. 184-192: dossier patrístico y 192-197: dossier litúrgico). Nos beneficiamos, en ocasiones, de la documentación contenida en este estudio.

${ }^{34}$ Cfr. DH 623 y 624.

35 «Llamamos predestinación al decreto eterno de Dios (aeternum Dei decretum) por el que Él determinó ante sí mismo lo que quería hacer con cada hombre. Porque no todos fueron creados en una condición semejante: pues algunos fueron predestinados (preordinatur) a la vida eterna y otros a la condena eterna. Y puesto que cada hombre ha sido creado en vista de uno u otro de estos fines, por eso decimos que ha sido predestinado a la vida o a la muerte». JUAN CALVINO, Institutio christianae religionis, III,XXI,5: curavit Tholuck, A., Pars altera, Berolini: Eichler, 1835 (traducción nuestra del texto latino). Sobre la noción de predestinación en Calvino cfr. entre otros: cfr. Levering, M., Predestination. Biblical and Theological Paths, Oxford-New York: Oxford University Press, 2011, 101-103; Muller, R. A., Christ and the Decree. Christology and Predestination in Reformed Theology from Calvin to Perkins, Grand Rapids (Mich): Baker Academic, 2008, 17-38. 
la cabeza del movimiento protestante en Ginebra, extraía como consecuencia la idea de que la muerte de Jesús no pudo tener lugar en favor de todos los hombres, sino sólo de los elegidos ${ }^{36}$. Tampoco faltaron ideas semejantes en el ámbito católico. Por ejemplo, Inocencio X tuvo que reaccionar contra las afirmaciones de Jansenio en su Augustinus, de las que se desprendía que Jesús había muerto sólo por los elegidos ${ }^{37}$.

Pero si la época moderna estuvo atravesada por tendencias rigoristas en materia de predestinación, hay que decir lo contrario del periodo más reciente. La carta del cardenal Arinze comunicando la decisión de ajustarse al texto latino en la fórmula de consagración, señalaba entre las ventajas del cambio la siguiente: «la expresión "por muchos" -afirmaba- mientras que se mantiene abierta a la inclusión de cada persona humana, refleja también el hecho de que esta salvación no ocurre en una forma mecánica sin la participación o voluntad propia de cada persona; más bien, se invita al creyente a aceptar en la fe el don que se le ofrece (...) y a vivirlo en modo tal que él pueda ser incluido entre esos "muchos", de los que el texto habla» ${ }^{38}$.

La expresión «por muchos» serviría pues para hacer frente a la idea, frecuente en la actualidad, de que, siendo Dios infinitamente misericordioso, no permitirá que ninguno se condene; que, en definitiva, todos terminan salvándose. Se trata de una idea a la que se aproximan también algunos teólogos de renombrada fama. En el ámbito de la Reforma, el teólogo suizo Karl Barth reinterpretó a mediados del siglo pasado la doctrina de Calvino. Según Barth existe efectivamente una «doble predestinación», como afirmaba Calvino, pero no se trata de la predestinación de unos pocos a la salvación (los elegidos) y de los demás a la reprobación, como propugnaba el reformador. La doble predestinación se refiere, dice Barth, al «sí̀ y al «no» de Dios: el «sí» de Dios a la humanidad que él ha decidido crear y llamar a la comunión consigo, y el «no» de Dios al pecado que acaece en la historia y en la Pascua de Jesús, en la cual Dios toma sobre sí mismo nuestro pecado y lo condena en vistas al perdón. De este modo el

${ }^{36}$ Un estudio detallado de la cristología y la teología de la predestinación de Teodoro Beza en Muller, R. A., Christ and the Decree, Christology and Predestination in Reformed Theology from Calvin to Perkins, 78-96.

37 Concretamente, en la Bula Cum Occasione de Inocencio X se rechaza la idea jansenista de que «es semipelagiano sostener que Cristo murió por todos» (DH 2005). Medio siglo más tarde Inocencio XI se opuso a la afirmación de Quesnel de que «no existe gracia fuera de la Iglesia» (DH 2429).

38 Congregación para el Culto Divino, «Carta a los presidentes de las conferencias episcopales», 17-X-2006, Notitiae. Boletín de la congregación para el culto divino 42 (2006) 441-443. 
teólogo calvinista llega a considerar que ninguno puede negar la elección de la que ha sido objeto en Jesús, aunque de su conducta parezca poderse deducir lo contrario $^{39}$. Pero si todos han sido elegidos en Cristo con una elección soberana e infalible, parecería que no es posible condenarse. En ámbito católico se encuentran afirmaciones semejantes en la teología de Hans Urs von Balthasar. A partir de la idea de que no existe hombre alguno que no haya sido proyectado y llamado a la comunión con Dios en Cristo, Balthasar se interroga por el sentido de una libertad que, como la humana, puede oponerse al diseño divino. El teólogo suizo considera que un proyecto de ese tipo es posible porque Dios puede, en su amor tripersonal, hacerse cargo del pecado del hombre ${ }^{40}$. En la Trinidad eterna las Personas divinas renuncian a sí mismas y se donan por entero a las demás, por eso son también capaces de humillarse por amor en su relación con el mundo. De modo que el Verbo puede abajarse, identificarse con nosotros, pecadores, y cargar él mismo con nuestra lejanía de Dios. Pero si Cristo toma sobre sí la distancia divina que es fruto del pecado, el alejamiento de Dios, entonces, en cierto modo, encierra en su condición filial el camino mismo del pecador. Ciertamente Balthasar no llega a concluir de aquí que todos los hombres serán salvados, pero su teología anima a confiar que ningún hombre se condenará.

\subsection{Muchos/todos: una dialéctica resuelta en el amor}

Las posiciones que acabamos de comentar subrayan de tal modo la dimensión objetiva y divina de la salvación, que la respuesta de fe del hombre pierde consistencia. Es Dios quien decide lo importante en la salvación de cada uno. Dios decide, en su soberana libertad, quien se salva y quien no en el sistema de Calvino; y Dios también, encierra a todos en su invencible misericordia, en el pensamiento de Barth y, en último término, también de Balthasar. La muerte de Cristo traslada a la historia estas decisiones divinas en

39 Cfr. BarTh, K., Church Dogmatics II, 2, 345-349, citado en Davies, H., The Vigilant God. Providence in the Thought of Augustin, Aquinas, Calvin and Barth, New York: Peter Lang, 1992, 138. Sobre las nociones de elección y predestinación en Karl Barth, cfr. VAN DRIEL, E. C., «Election», en BURnETT, R. E. (ed.), The Westminster handbook to Karl Barth, Louisville (USA): Westminster John Knox Press, 2013, 57-60.

${ }^{40}$ Una presentación de algunas de estas ideas hecha por el propio autor en VON BALTHASAR, H. U., Teodramática, 2: Las personas del drama: El hombre en Dios, Madrid: Encuentro, 1990, 223-261. También: Von Balthasar, H. U, Teología de los tres días. El Misterio Pascual, Madrid: Encuentro, 2000. 
beneficio exclusivo de algunos (Godescalco, Calvino) o de todos (Barth, Balthasar: ambos tendencialmente).

La doctrina tradicional ha mantenido por lo general una línea más equilibrada, capaz de reconocer la importancia de los dos aspectos: la muerte de Cristo para salvar a los hombres y la necesidad de adherirse por la fe a esa muerte para recibir los frutos de salvación. Ha buscado modos de decir que contuvieran ambos aspectos. S. Pedro Damián, por ejemplo, distingue entre el poder redentor del sacrificio de Cristo y su acción eficaz en los creyentes. Hablando de la sangre de Cristo, escribe: «pro solis destinatis effusus est quoad efficatiam; pro omnibus quoad sufficientiam $\gg^{41}$. Es decir: la potencia redentora de la muerte de Cristo es suficiente para salvar a todos, pero es eficaz sólo en los que se salvan (en los «elegidos», como era frecuente decir). Santo Tomás recoge la idea en su Comentario a las Sentencias ${ }^{42}$, y ésta es también la posición del Catecismo Romano: «Porque, considerando su eficacísima virtud, debemos admitir que Cristo derramó su sangre por la salud de todos; mas, si atendemos al fruto que de ella consiguen los hombres, habremos de admitir que no todos la participan efectivamente, sino sólo muchos» ${ }^{43}$. Se trata de una distinción aceptable, que muestra bien que la salvación puede llegar a todos, pero que de hecho no es «automática»: requiere la cooperación del hombre; sin embargo, necesita todavía ser precisada.

En primer lugar hay que precisar mejor en qué consiste el beneficio redentor de la sangre de Cristo. La perspectiva que acabamos de mencionar parece entender este beneficio como salvación última y definitiva. Sin duda los que se salvan han recibido la vida eterna en virtud de la sangre derramada por Jesús, la cual muestra en ellos toda su eficacia. Pero esto no significa que esa eficacia se manifieste sólo ahí. Naturalmente, también todos los que son justificados por los sacramentos o en relación con los sacramentos, se benefician de esa sangre derramada. Pero tampoco la eficacia de la muerte de Jesús se queda ahí. Existe una acción del Espíritu Santo que asiste a cada hombre con

41 Pedro Damián, Expositio Canonis Missae: PL 145.884b.

${ }^{42}$ Cfr. Tomás De Aquino, IV Sent. d. 8 q. 2 art. 2 qa 3 arg. 7: «Praeterea, quod dicitur: pro vobis et pro multis effundetur, aut accipitur de effusione quantum ad sufficientiam, aut quantum ad efficaciam. Si quantum ad sufficientiam, sic pro omnibus effusus est, non solum pro multis; si autem quantum ad efficaciam, quam habet solum in electis, non videtur distinguendum fuisse inter apostolos et alios».

${ }^{43}$ El «Catecismo Romano» del Concilio de Trento (traducción y notas de Martín Hernández, P.), Madrid: BAC, 1951, n. 423. 
luces y gracias actuales, orientándole hacia el fin para el que ha sido creado: la comunión con Dios, la vida eterna ${ }^{44}$. Esta acción de la Tercera Persona acompaña constantemente a las personas (no obstante el pecado de origen y las faltas personales) y, aunque requiere la cooperación del hombre para producir frutos, no depende del hombre en su existencia sino que es fruto de la Pasión y muerte de nuestro Señor, de su sangre derramada por todos ${ }^{45}$. Esta gracia tiene por finalidad la de acercar a los hombres a la plenitud de la verdad en Cristo y en su Iglesia. Por tanto, la eficacia redentora de Cristo se hace presente verdaderamente en la vida de cada hombre y no sólo en la vida del creyente. $\mathrm{Y}$ también, por tanto, hay que distinguir entre los que reciben beneficios de la muerte de Jesús (todos los hombres) y los que los reciben de modo tal que alcanzan la salvación (los que se salvan: los elegidos). Esto hace ver con mayor claridad que la fórmula: «sangre derramada por todos» es doctrinalmente correcta.

Además, la gracia que Dios concede a los fieles cristianos establece, en virtud de la sangre de Cristo, una relación con todos los hombres, con el mundo. Esa intencionalidad hacia la salvación del mundo forma parte de la vocación de la Iglesia, como formaba parte ya de la misión de Israel, el pueblo elegido $^{46}$. A través de la Iglesia, la gracia y la salvación se derraman sobre el mundo. Por eso es lógico pensar que, cuando -al trasmitir las palabras de Cristo en la Última Cena- Lucas habla de la sangre «derramada por vosotros» (o Pablo del cuerpo entregado «por vosotros»), en referencia a los discípulos, no limitan el «vosotros» sólo a los oyentes circunstanciales de Jesús, sino que lo aplican a todos los que, en virtud de la misión, vendrían a recibir el cuerpo y la sangre de Cristo en la comunidad de los discípulos ${ }^{47}$. Saben también que esa

${ }^{44}$ Cfr. sobre esto mi estudio: «La redenzione come apertura della vita umana alla grazia», Annales Theologici 29/1 (2015) 123-138.

45 «La obra redentiva de Cristo afecta a todos los seres humanos en su relación a su destino final porque todos están llamados a la vida eterna. Por el derramamiento de su sangre en la cruz, Cristo estableció una nueva alianza, un régimen de gracia, que se dirige a toda la humanidad. Cada uno de nosotros puede decir con el Apóstol: "Me amó y se entregó por mí" (Gal 2,20). Cada uno está llamado a participar por adopción en la filiación propia de Cristo. Dios no hace esta llamada sin proveer la capacidad de responder a ella. Por eso, el Vaticano II puede enseñar que no hay ningún ser humano, ni siquiera "los que ignoran sin culpa el Evangelio", que no sea tocado por la gracia de Cristo». Comisión TeOlógica InTERnaCional, Cuestiones selectas sobre Dios Redentor (1994), Parte IV, n. 47: CTI, Documentos 1969-1996, Madrid, 1998, 499-556 (548).

${ }^{46}$ Cfr. Wright, N. T., Paul and the faithfulness of God, Minneapolis: Fortress Press, 2013, 1208.

47 También el mandato de Cristo de celebrar la eucaristía en su memoria subraya este aspecto. Cfr. Lc 22,19; 1 Cor 11,24.25. 
comunidad, la Iglesia, está abierta a todos los hombres y busca la salvación de cada uno de ellos. Esos círculos concéntricos (vosotros, muchos, todos) encuadran mejor la cuestión de los destinatarios de la sangre derramada, que la antigua división entre elegidos y condenados. Responden mejor al deseo de Jesús, que dio a algunos la misión de predicar a muchos, para que el Evangelio pudiera difundirse y alcanzar a todos.

Éste es, pienso, el modo de ver la cuestión de Benedicto XVI. Entiende que el significado de «por muchos» en los evangelios de Mateo y Marcos está en continuidad con el «por vosotros» de Pablo y de Lucas, y, por tanto, que ese «muchos» se refiere a los discípulos de Cristo que vendrán a la Iglesia a lo largo de los tiempos. Pero, precisamente esa continuidad hace que no se pierda de vista el horizonte universal de la misión. «Los muchos -afirma Benedicto XVI- tienen responsabilidad por todos. La comunidad de los muchos debe ser luz en el candelero, ciudad puesta en lo alto de un monte, levadura para todos. Ésta es una vocación que concierne a cada uno de manera totalmente personal. Los muchos, que somos nosotros, deben llevar consigo la responsabilidad por el todo, conscientes de la propia misión ${ }^{48}$.

En definitiva, Cristo murió por todos los hombres y todos reciben por medio de su Espíritu, con la cooperación de la Iglesia, los medios necesarios para alcanzar la salvación, el impulso para formar parte de esos «muchos» que han recibido en sus vidas a Jesús ${ }^{49}$. Pero, a la vez, esos «muchos» que a lo largo de los tiempos creerán en Cristo tienen la misión de llevar el evangelio hasta los confines de la tierra, pues ése es el deseo de Dios: que todos se salven y lleguen a conocer la verdad (cfr. 1 Tim 2,4). De modo que los cristianos forman con los demás hombres parte de un único y mismo proyecto de salvación, nacido en Dios Padre, regado por la sangre de Cristo y fecundado por los dones del Espíritu santo. La nueva traducción de la fórmula de la consagración no modifica en modo alguno la doctrina de la Iglesia, pero subrayando que la sangre fue derramada por «muchos» se apela a la libertad del hombre, a la necesidad de responder generosamente al amor de Cristo, con una respuesta que no tiene más confines que los señalados por la multiforme acción salvadora del Espíritu.

48 Benedicto XVI, «Carta al Presidente de la Conferencia Episcopal Alemana sobre la traducción de "pro multis"», 14-IV-2012, Pastoral litúrgica. Documentación. Información 328-329 (2012) 86.

49 Sobre estos aspectos: DucaY, A., «Extra Ecclesiam nulla salus. Prospettiva dogmatica», Annales Theologici 25 (2011) 371-390. 


\section{Bibliografía}

BeAton, R., «Isaiah in Matthew's Gospel», en Moyise, S. y Menken, M. J. J. (eds.), Isaiah in the New Testament, London: T\&T Clark, 2005, 63-78.

Benedicto XVI, «Carta al Presidente de la Conferencia Episcopal Alemana sobre la traducción de "pro multis"», 14-IV-2012, Pastoral litúrgica. Documentación. Información 328-329 (2012) 81-86.

Benedicto XVI/Ratzinger, J., Fesús de Nazaret: Desde la Entrada en Ferusalén hasta la Resurrección, Madrid: Encuentro, 2011, 125-172.

Bover, J. M. y O’Callaghan, J., Nuevo Testamento Trilingüe, Madrid: BAC, 1994.

Bovon, F., El Evangelio según San Lucas, Salamanca: Sígueme, 2010.

Casciaro, J. M. (ed.), Sagrada Biblia V, Pamplona: Eunsa, 2008.

Childs, B. S., Isaiah, Louisville: Westminster John Knox Press, 2001.

Comisión Teológica Internacional, Cuestiones selectas sobre Dios Redentor (1994): CTI, Documentos 1969-1996, Madrid, 1998, 499-556.

Conferencia Episcopal Española, Mensaje de la Comisión Episcopal de Liturgia, 20-IV-2016.

CONGREgación PARA El CUlto Divino, «Carta a los presidentes de las conferencias episcopales», 17-X-2006, Notitiae. Boletín de la congregación para el culto divino 42 (2006) 441-443.

CONGREgación PARA El CUlto Divino, «Liturgiam authenticam», 28-III2001, Notitiae. Boletín de la congregación para el culto divino 38 (2002) 65-119.

Davies, H., The Vigilant God. Providence in the Thought of Augustin, Aquinas, Calvin and Barth, New York: Peter Lang, 1992.

Davies, W. C. y Allison, D. C., The Gospel According to Saint Matthew, London: T\&T Clark, 2004.

DucaY, A., «Extra Ecclesiam nulla salus. Prospettiva dogmatica», Annales Theologici 25 (2011) 371-390.

DUCAY, A., «La redenzione come apertura della vita umana alla grazia», Annales Theologici 29/1 (2015) 123-138.

FitZMYer, J. A., El Evangelio según Lucas, Madrid: Cristiandad, 2005.

Gagliardi, M., recensión de Hauke, M., «Vesato per molti: Studio per una fedele traduzione del "pro multis" nelle parole della consecrazione», Siena: Cantagalli, 2008, en Alpha Omega 11 (2008) 495-496. 
GIRAUDO, C., «"Pro vobis et pro multis". La parole istituzionali tra quello che ha detto Gesù e quello che possiamo leggervi noi», Gregorianum 93 (2012) 677-709.

GNilka, J., El Evangelio según San Marcos, Salamanca: Sígueme, 1986.

Hauke, M., «Shed for the Many. An Accurate Reading of the Pro Multis in the Formula of Consecration», Antiphon 14 (2010) 169-229.

Jeremias, J., La Última Cena: Palabras de Fesús, Madrid: Cristiandad, 1980.

KLAUCK, H. J., «Lord's supper», Anchor Bible Dictionary 4 (1992) 362-372.

Levering, M., Predestination. Biblical and Theological Paths, Oxford-New York: Oxford University Press, 2011.

LuZ, U., El Evangelio según San Mateo, Salamanca: Sígueme, 2005.

Monzio Compagnoni, G., «La formula "pro vobis et pro multis". Note sull'origine e considerazioni sulla traduzione», Ephemerides Liturgicae 128 (2014) 48-103.

Muller, R. A., Christ and the Decree. Christology and Predestination in Reformed Theology from Calvin to Perkins, Grand Rapids (Mich): Baker Academic, 2008.

O’Toole, R. F., «Last supper», Anchor Bible Dictionary 4 (1992) 234-241.

Pesch, R., Il Vangelo di Marco, Brescia: Paideia, 1982.

PIERI, F., Per una moltitudine. Sulla traduzione delle parole eucaristiche, Bologna: Dehoniane, 2012.

Pirot, L. y Clamer, A., La Sainte Bible: Saint Matthieu - Saint Marc, Paris: Letouzey et Ané, 1950.

Prosinger, F., «Le sang de l'Alliance répandu "pour tous" ou "pour beaucoup?”», Sedes Sapientiae 87 (2004) 53-70.

Uricchio, F. M. y Stano, G. M., Vangelo secondo San Marco, Roma: Marietti, 1966.

VAN Driel, E. C., «Election», en BuRnETT, R. E. (ed.), The Westminster handbook to Karl Barth, Louisville (USA): Westminster John Knox Press, 2013, 57-60.

VANHOYE, A., «La traducción del pro multis», Phase 303 (2011) 311-317.

VON Balthasar, H. U., Teodramática, 2: Las personas del drama: El hombre en Dios, Madrid: Encuentro, 1990.

Von Balthasar, H. U., Teología de los tres días. El Misterio Pascual, Madrid: Encuentro, 2000.

Wright, N. T., Paul and the faithfulness of God, Minneapolis: Fortress Press, 2013. 
